\section{Reutilização de resíduo sólido industrial, constituído por areias de fundição, na fabricação de tijolos maciços e peças decorativas}

\author{
Javier Mazariegos Pablos
}

Engenheiro elétrico, professor doutor do Departamento de Arquitetura e Urbanismo da Escola de Engenharia de São Carlos (EESC-USP), Avenida Trabalhador Sancarlense, 400, CEP 13566-590, São Carlos, SP, (16) 33739294, pablos@sc.usp.br

\section{Eduvaldo Paulo Sichieri}

Engenheiro de materiais, professor titular do Departamento de Arquitetura e Urbanismo da Escola de Engenharia de São Carlos (EESC-USP), Avenida Trabalhador Sancarlense, 400, CEP 13566-590, São Carlos, SP, (16) 33739294, sichieri@sc.usp.br

\section{Rafaela Lino Izeli}

Graduanda em Arquitetura e Urbanismo no Departamento de Arquitetura e Urbanismo da Escola de Engenharia de São Carlos (EESC-USP), Avenida Trabalhador Sancarlense, 400, CEP 13566-590, São Carlos, SP, (16) 33739294, rafaela.izeli@ hotmailcom.

\title{
Resumo
}

O presente trabalho é resultado de pesquisa que investigou a viabilidade técnica da reutilização do resíduo sólido gerado pelas areias de fundição aglomeradas com argila, para aplicação no setor da construção civil e em peças decorativas. Para isso, a investigação estabeleceu uma metodologia, a qual avaliou a estabilização do resíduo em matrizes solidificadas de cimento Portland, melhoradas através da adição de sílica ativa e/ou aditivo superplastificante. Duas composições foram utilizadas na fabricação de tijolos maciços e na confecção de peças decorativas. Os resultados obtidos comprovam a viabilidade técnica para aplicação dos tijolos na execução de alvenarias e para a fabricação de peças decorativas, as quais apresentaram excelente valor agregado e potencial de comercialização.

Palavras-chave: resíduos sólidos industriais, solidificação/estabilização, reutilização.

ntre todos os problemas que a humanidade enfrenta, um dos principais é a necessidade de minimizar os efeitos da degradação ambiental e social. Isso é possível via desenvolvimento e aplicação de pesquisas científicas e tecnológicas, que visem encontrar soluções para os problemas gerados pelo progresso e que consigam repercussões positivas para o meio ambiente e para o aprimoramento da cidadania, no sentido de obter uma melhor qualidade de vida para as próximas gerações. Dentro desse contexto, uma das questões de fundamental importância para o ser humano é a necessidade de reaproveitar, ou reciclar o lixo, os rejeitos e os resíduos por ele gerados, como forma de recuperar matéria e energia, visando minimizar a utilização de recursos naturais e uma menor degradação do meio ambiente. Além disso, estabelece a possibilidade de gerar empregos e riquezas, proporcionando melhoria nas condições de vida das comunidades.

As siderúrgicas, em geral, são consideradas empresas que produzem grandes efeitos nocivos ao meio ambiente, tanto pela utilização de grande quantidade de recursos naturais, quanto devido à geração de alto volume de substâncias estranhas ao meio. Particularmente, as indústrias de fundição geram vários tipos de resíduos, entre eles um tipo de resíduo sólido proveniente do descarte das denominadas 
"areias de fundição aglomeradas com argila", objeto de estudo no presente trabalho.

Segundo inventário realizado pela CETESB Companhia de Tecnologia de Saneamento Ambiental (1999), o Estado de São Paulo produz por ano 512.196 toneladas de resíduos sólidos perigosos, dos quais $53 \%$ são tratados, $31 \%$ armazenados e $16 \%$ depositados no solo. Além disso, são produzidas ainda 19.519.026 toneladas de resíduos não inertes e 1.012.899 toneladas de resíduos inertes.

Para as indústrias brasileiras, gerenciar os resíduos transformou-se em um dos principais desafios enfrentados. É necessário caracterizar e quantificar quais são os resíduos industriais perigosos, nãoperigosos e inertes gerados, além de definir as etapas de manuseio, armazenamento, transporte, tratamento, reutilização e disposição final.

Por outro lado, a implantação de uma política de crescimento sustentável do país abrange, de forma direta, a tratativa da questão dos resíduos sólidos industriais, sendo que o desenvolvimento e o domínio de tecnologias e de técnicas de reutilização desses resíduos implicarão, sem dúvida, em um crescimento industrial, comercial e econômico.

O principal objetivo da presente investigação foi estabelecer uma metodologia para a verificação da viabilidade técnica de reutilização do resíduo sólido industrial, gerado pelas areias de fundição, na fabricação de elementos construtivos e decorativos, visando aplicação na construção civil e na decoração de ambientes.

Neste trabalho foi adotada a técnica de solidificação/ estabilização em matrizes de cimento Portland, devido à simplicidade do processo e ao baixo custo, além disso, é particularmente recomendada para resíduos metálicos (SAITO, et.al, 1985; apud HANNA, 1996). Segundo Poon et al. (1986), a tecnologia de solidificação/estabilização de resíduos é um pré-tratamento indutor de reações químicas e mecanismos físicos que fixam elementos ou compostos tóxicos em polímeros impermeáveis ou em cristais estáveis. Alguns pesquisadores vêm utilizando o processo de estabilização de resíduos perigosos ou não perigosos, contendo metais pesados, através da solidificação em matrizes de cimento Portland, assim como: MERRIT \& BATCHELOR (1993), WILK
(1997), CONNER (1997), ADASKA (1998) e BHATTY

(1999). No Brasil, alguns trabalhos podem ser citados: CLAUDIO (1987), HANNA (1990 e 1996), PABLOS (1995), OLIVEIRA (1996), MARAGNO (1999), PINTO (2001), SILVA (2002) e ALBERONI (2006).

\section{Metodologia}

A partir de uma avaliação da composição do resíduo sólido de areia de fundição aglomerada com argila e, através da técnica de estabilização por solidificação em matrizes de cimento Portland, o estudo investigou composições para introduzir a reutilização do resíduo na fabricação de tijolos maciços, pelo processo de prensagem, e na confecção de peças decorativas, pelo processo de adensamento mecânico (vibração).

Para isso, o trabalho estabelece a seguinte estrutura metodológica:

- Conhecimento da fonte geradora;

- Classificação do resíduo sólido;

- Caracterização do resíduo para reutilização em artefatos de cimento;

- Caracterização do resíduo como agregado para utilização na composição de argamassas de cimento;

- Verificação do desempenho das matrizes solidificadas compostas com o resíduo: resistência à compressão, absorção de água, permeabilidade ao ar e solubilização;

- Utilização das composições adequadas, de acordo com propriedades mecânica e física e eficiência de estabilização, na fabricação de tijolos maciços e elementos decorativos:

- Determinação das propriedades mecânica e física dos tijolos maciços, visando utilização em alvenarias sem função estrutural, e verificação da eficiência de estabilização do resíduo.

\section{Fonte geradora}

O resíduo sólido é proveniente da desmoldagem das areias de fundição aglomeradas com argila empregadas pela indústria Tecumseh do Brasil Ltda 
Figura 1: Fluxograma simplificado dos processos de fundição e de geração do resíduo. Fonte: Javier Mazariegos Pablos. para obtenção de peças metálicas utilizadas no processo de fabricação de seus produtos. Seu setor de fundição atinge uma produção aproximada de 2500 toneladas de peças metálicas de ferro cinzento por mês, para isso, descarta cerca de 500 toneladas de resíduo sólido proveniente do desmonte dos moldes de areia. A empresa está localizada na cidade de São Carlos, Estado de São Paulo, e deposita os resíduos sólidos gerados em um aterro industrial adequado para essa finalidade, a um custo aproximado de $\mathrm{R} \$ 200,00$ por tonelada.

A areia-base utilizada na composição das areias de fundição é do tipo silicosa, encontrada em jazidas da região e fornecida pela Mineração Jundú. A argila utilizada como aglomerante é a bentonita sódica ativada, fornecida principalmente pela Bentonit União Nordeste S.A.

Como aditivo utiliza-se, na composição das areias de fundição, o carvão mineral em pó, participando da mistura em pequenas proporções. As areias de fundição empregadas possuem composição conforme apresentado na tabela 1:
Tabela 1 - Composição das areias de fundição

\begin{tabular}{ll} 
Componente & Proporção em massa (\%) \\
\hline Areia silicosa & 83 a 89 \\
Argila (bentonita) & 8 a 13 \\
Carvão mineral & 0,6 a 1,0 \\
Água & 3 \\
\hline
\end{tabular}

Fonte: Tecumseh do Brasil Ltda.

Com o vazamento do metal líquido nos moldes, a areia de fundição passa por um processo de queima a uma temperatura próxima de 1400 OC. Nessa temperatura a areia-base não se funde, mantendo a estrutura granular cristalizada, porém grande parte da argila perde suas características aglomerantes, transformando-se em material pulverulento inerte, ou aderindo aos grãos de areia. A solidificação do metal envolve formação de gases, que são liberados passando através do molde, carregando consigo partículas do metal utilizado, os quais se solidificam dentro do molde e farão parte constituinte das areias de fundição de descarte.

Como podemos verificar na figura 1, as areias de fundição usadas são reaproveitadas, através de um

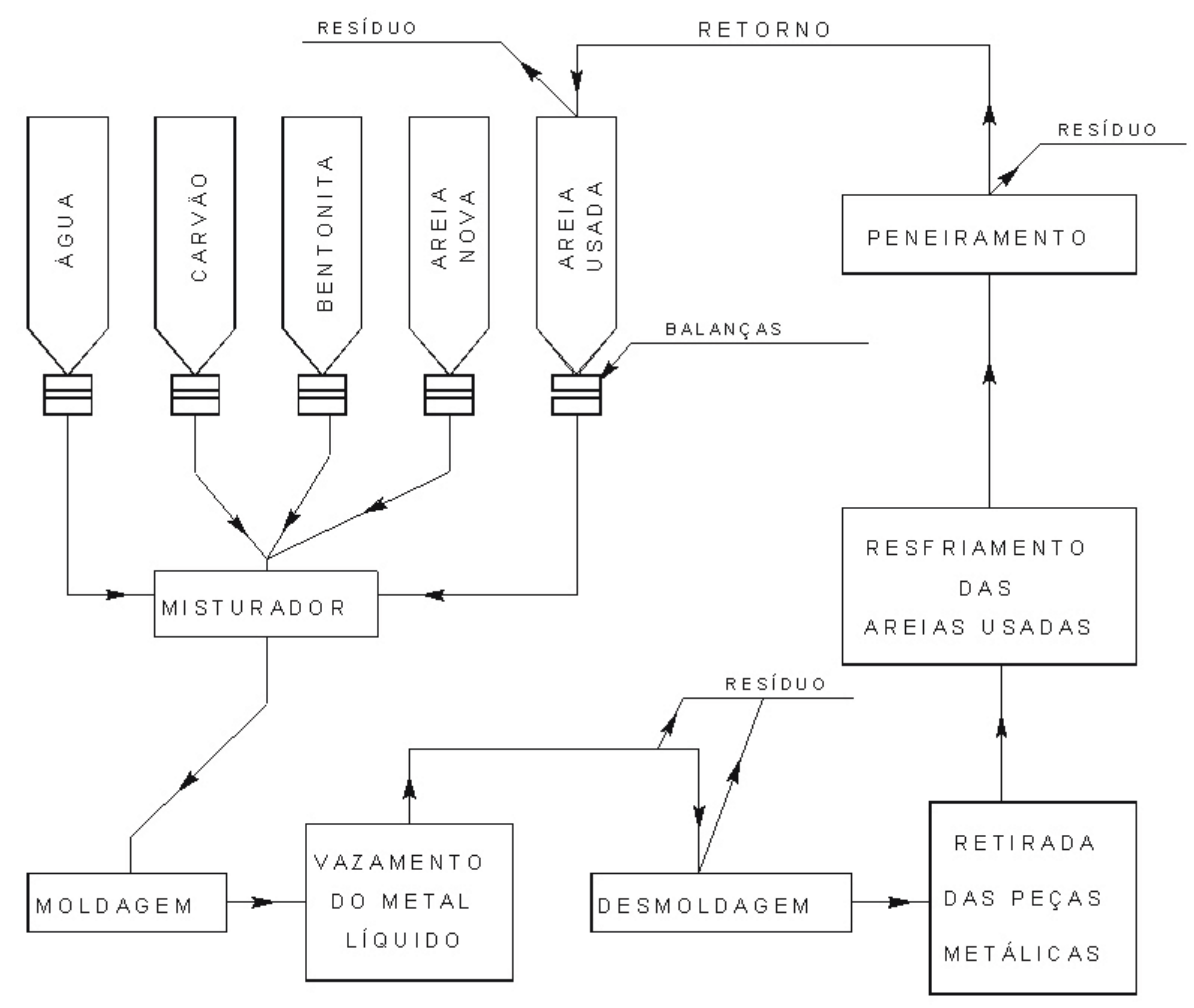


processo de recuperação e regeneração. As areias de fundição descartadas, ou seja, as que realmente se transformam em resíduo, são provenientes de pedaços dos moldes que se desagregam durante o percurso nas esteiras rolantes e caem no chão, assim como do esvaziamento parcial do silo, destinado ao armazenamento das areias usadas, que é efetuado quando se encontra excessivamente cheio.

\section{Classificação do resíduo sólido}

Para efetuar a classificação do resíduo, foram empregadas as especificações estabelecidas pela ABNT, como segue:

- NBR 10007 (2004) - Amostragem de resíduo sólido;

- NBR 10006 (2004) - Procedimento para obtenção de extrato solubilizado de resíduos sólidos;

- NBR 10005 (2004) - Procedimento para obtenção de extrato lixiviado de resíduos sólidos;

- NBR 10004 (2004) - Resíduos sólidos: classificação.

Segundo a norma ABNT NBR-10004, a classificação de resíduos sólidos envolve a identificação do processo ou atividade que thes deu origem e de seus constituintes e características e a comparação destes constituintes com listagens de resíduos e substâncias cujo impacto à saúde e ao meio ambiente é conhecido.

Os ensaios referentes foram realizados no Laboratório de Saneamento do Departamento de Hidráulica e Saneamento da Escola de Engenharia de São Carlos - USP.

Os parâmetros que estão em desacordo com o Limite Máximo (L.M.) estabelecido pela ABNT NBR-10004 (2004), em seu anexo G, referente aos padrões para o ensaio de solubilização, estão grifados na tabela 2.

A análise dos resultados indica que o resíduo sólido deve ser classificado como classe II A - "não perigoso e não inerte".
Tabela 2 - Análise do extrato solubilizado do resíduo (ABNT)

\begin{tabular}{|c|c|c|c|}
\hline Elemento & Unidade & $\begin{array}{c}\text { Solubilização } \\
\text { do resíduo } \\
\text { (mg/L) }\end{array}$ & $\begin{array}{c}\text { Solubilização } \\
\text { (mg/L) } \\
\text { L.M. }\end{array}$ \\
\hline Alumínio & $\mathrm{mg} \mathrm{Al} / \mathrm{L}$ & 3,64 & 0,2 \\
\hline Arsênio & $\mathrm{mg} \mathrm{As} / \mathrm{L}$ & 0,01 & 0,01 \\
\hline Bário & mg Ba/L & $<0,30$ & 0,7 \\
\hline Cádmio & $\mathrm{mg} \mathrm{Cd} / \mathrm{L}$ & $<0,004$ & 0,005 \\
\hline Chumbo & $\mathrm{mg} \mathrm{Pb} / \mathrm{L}$ & $<0,004$ & 0,01 \\
\hline Cobre & $\mathrm{mg} \mathrm{Cu} / \mathrm{L}$ & 0,263 & 2,0 \\
\hline Cromo Total & $\mathrm{mg} \mathrm{Cr} / \mathrm{L}$ & 0,12 & 0,05 \\
\hline Ferro & $\mathrm{mg} \mathrm{Fe} / \mathrm{L}$ & 3,31 & 0,3 \\
\hline Manganês & $\mathrm{mg} \mathrm{Mn} / \mathrm{L}$ & $<0,01$ & 0,1 \\
\hline Mercúrio & $\mathrm{mg} \mathrm{Hg} / \mathrm{L}$ & $<0,001$ & 0,001 \\
\hline Prata & $\mathrm{mg} \mathrm{Ag} / \mathrm{L}$ & $<0,009$ & 0,05 \\
\hline Selênio & $\mathrm{mg} \mathrm{Se} / \mathrm{L}$ & $<0,003$ & 0,01 \\
\hline Sódio & $\mathrm{mg} \mathrm{Na} / \mathrm{L}$ & 71,2 & 200,0 \\
\hline Zinco & $\mathrm{mg} Z \mathrm{n} / \mathrm{L}$ & 0,017 & 5,0 \\
\hline Cianetos & $\mathrm{mg} C \mathrm{CN} / \mathrm{L}$ & $<0,042$ & 0,07 \\
\hline Cloretos & $\mathrm{mg} \mathrm{Cl} / \mathrm{L}$ & 61,3 & 250,0 \\
\hline Fenóis & $\mathrm{Mg} \mathrm{C} 6 \mathrm{H} 5 \mathrm{OH} / \mathrm{L}$ & $<0,001$ & 0,01 \\
\hline Fluoretos & $\mathrm{mg} \mathrm{F/L}$ & 0,19 & 1,5 \\
\hline Nitratos & $\mathrm{mg} \mathrm{N} / \mathrm{L}$ & $<0,85$ & 10,0 \\
\hline Sulfatos & $\mathrm{mg} \mathrm{SO} / \mathrm{L}$ & 53,0 & 250,0 \\
\hline Surfactantes & mg LAS/L & $<0,03$ & 0,5 \\
\hline
\end{tabular}

L.M.- Limite máximo estabelecido pela ABNT NBR10004 (2004).

Tabela 3 - Análise do extrato lixiviado do resíduo (ABNT)

\begin{tabular}{llll} 
Elemento & Unidade & $\begin{array}{c}\text { Lixiviação } \\
\text { do resíduo } \\
(\mathrm{mg} / \mathrm{L})\end{array}$ & $\begin{array}{c}\text { Lixiviação } \\
\text { (mg/L) } \\
\text { L.M. }\end{array}$ \\
Arsênio & $\mathrm{mg} \mathrm{As} / \mathrm{L}$ & $<0,001$ & 1,0 \\
Bário & $\mathrm{mg} \mathrm{Ba} / \mathrm{L}$ & $<0,03$ & 70,0 \\
Cádmio & $\mathrm{mg} \mathrm{Cd} / \mathrm{L}$ & $<0,004$ & 0,5 \\
Chumbo & $\mathrm{mg} \mathrm{Pb} / \mathrm{L}$ & $<0,044$ & 1,0 \\
\hline Cromo Total & $\mathrm{mg} \mathrm{Cr} / \mathrm{L}$ & 0,034 & 5,0 \\
Mercúrio & $\mathrm{mg} \mathrm{Hg} / \mathrm{L}$ & $<0,001$ & 0,1 \\
\hline Prata & $\mathrm{mg} \mathrm{Ag} / \mathrm{L}$ & $<0,009$ & 5,0 \\
Selênio & $\mathrm{mg} \mathrm{Se} / \mathrm{L}$ & $<0,003$ & 1,0 \\
\hline Fluoretos & $\mathrm{mg} \mathrm{F} / \mathrm{L}$ & $<0,1$ & 150,0 \\
\hline
\end{tabular}

L.M.- Limite máximo estabelecido pela ABNT NBR10004 (2004).

\section{Caracterização do resíduo para reutilização}

A Companhia de Tecnologia de Saneamento Ambiental, do Estado de São Paulo, em Decisão de Diretoria n0 152/2007/C/E de 08 de agosto de 2007, publicou o documento intitulado "Procedimentos para Gerenciamento de Areia de Fundição" - CETESB (2007), no qual, estabelece os seguintes procedimentos para avaliação de propostas de reutilização do resíduo areia de fundição na fabricação de artefatos de cimento:

a) o resíduo areia de fundição deverá ser classificado como classe II-A ou II-B, de acordo com a norma ABNT NBR 10004/2004. 
b) o resíduo areia de fundição deverá apresentar concentrações de poluentes no extrato lixiviado, obtido conforme a norma ABNT NBR 10005/2004, menores ou iguais às concentrações máximas constantes na Tabela: "Concentração Máxima de Poluentes no Lixiviado".

c) o resíduo areia de fundição deverá apresentar concentrações de poluentes, no extrato lixiviado neutro, menores ou iguais às concentrações máximas constantes na Tabela: "Concentração Máxima de Poluentes no Lixiviado Neutro". Sendo que, neste procedimento o resíduo areia de fundição deverá apresentar $\mathrm{pH}$ na faixa entre 5,0 e 10,0 .

d) o extrato solubilizado do resíduo areia de fundição não deve apresentar toxicidade frente ao teste de toxicidade aguda com a bactéria luminescente Vibrio fischeri. O teste deverá ser realizado de acordo com a norma técnica CETESB L5.227, em dose única máxima $(81,9 \%)$, com 5 réplicas, e o resultado deverá ser expresso em porcentagem de inibição média e desvio padrão, após 15 minutos de inibição. As amostras que apresentarem a média da porcentagem de inibição superior a $20 \%$ serão consideradas como tóxicas.

O teste de toxicidade aguda com a bactéria luminescente Vibrio fischeri, para 5 amostras, apresentou média de inibição de 15,4\% e desvio padrão de 1,67.

Nas tabelas 4 e 5 estão relacionados os resultados da análise do extrato lixiviado neutro e do extrato lixiviado, com as concentrações máximas estabelecidas pela CETESB (2007).

Tabela 4 - Análise do extrato lixiviado neutro (CETESB)

\begin{tabular}{|lll|}
\hline Elemento & $\begin{array}{l}\text { Lixiviação Neutra } \\
(\mathrm{mg} / \mathrm{L})\end{array}$ & $\begin{array}{c}\text { Concentração } \\
\text { Máxima }(\mathrm{mg} / \mathrm{L})\end{array}$ \\
\hline Cloreto & 38,0 & 2500,0 \\
\hline Cobre & 0,07 & 2,5 \\
\hline Cianeto & $<0,001$ & 2,0 \\
\hline Fluoreto & 0,05 & 14,0 \\
\hline Ferro & 14,30 & 15,0 \\
\hline Manganês & 0,30 & 0,5 \\
\hline Níquel & $<0,008$ & 2,0 \\
\hline Fenóis (total) & 0,011 & 3,0 \\
\hline Sódio & 44,0 & 2500,0 \\
\hline Sulfato & 64,0 & 2500,0 \\
\hline Sulfito (total) & 3,5 & 5,0 \\
\hline Sólidos Totais & 1723,0 & 5000,0 \\
\hline Zinco & 1,32 & 25,0 \\
\hline pH & 6,85 & \\
\hline
\end{tabular}

Tabela 5 - Análise do extrato lixiviado (CETESB)

\begin{tabular}{llc} 
Elemento & Lixiviação $(\mathrm{mg} / \mathrm{L})$ & $\begin{array}{c}\text { Concentração } \\
\text { Máxima }(\mathrm{mg} / \mathrm{L})\end{array}$ \\
\hline Arsênio & $<0,001$ & 0,50 \\
\hline Bário & $<0,03$ & 10,00 \\
\hline Cádmio & $<0,004$ & 0,10 \\
\hline Chumbo & $<0,044$ & 0,50 \\
\hline Cromo Total & 0,034 & 0,50 \\
\hline Mercúrio & $<0,001$ & 0,02 \\
\hline Selênio & $<0,003$ & 0,10 \\
\hline
\end{tabular}

\section{Caracterização do Resíduo como Agregado}

A investigação adotou a tecnologia de encapsulação do resíduo através da aplicação da técnica de estabilização por solidificação em matrizes de cimento Portland. Isso faz com que o resíduo passe a desempenhar o papel de agregado na composição de argamassas.

A qualidade dos agregados, utilizados na composição de argamassas de cimento Portland, pode ser avaliada através de algumas características da sua composição, principalmente no que diz respeito à quantidade de substâncias nocivas (materiais pulverulentos, torrões de argila, materiais carbonosos e impurezas orgânicas). Também, é importante conhecer alguns índices físicos (composição granulométrica, massa específica, massa unitária e teor de umidade), os quais auxiliam o estudo de dosagem das argamassas.

A caracterização do resíduo como agregado foi realizada de acordo com os procedimentos estabelecidos pela ABNT NBR-7211 - Agregados para concreto - especificação (2005). Todos os ensaios envolvidos nesta etapa foram realizados no Laboratório de Construção Civil do Departamento de Arquitetura e Urbanismo - EESC - USP.

Em todos os procedimentos realizados com a presença do resíduo, desta etapa em diante do trabalho, o mesmo passou por um processo de secagem ao ar livre, através do seu espalhamento e exposição aos raios solares durante no mínimo seis horas. Após esta secagem, o resíduo sofreu um peneiramento, em peneira com malha de abertura 4,8 $\mathrm{mm}$, sendo que somente ficaram retidos na peneira alguns poucos pedaços de metal, correspondente a aproximadamente 0,01\% da massa total peneirada. 


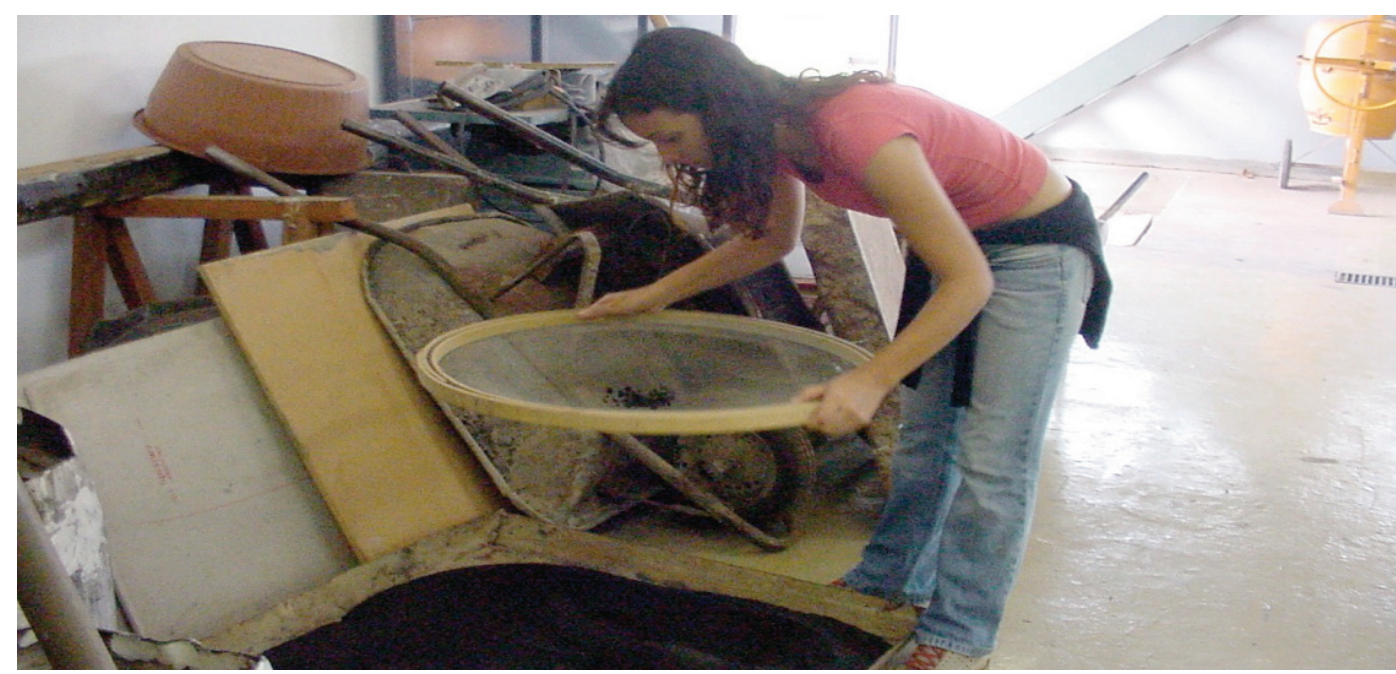

Figura 2: Processo de peneiramento do resíduo. Fonte: Javier Mazariegos Pablos.
A seguir estão relacionados os resultados obtidos:

- Teor de materiais pulverulentos: $8,8 \%$

- Teor de torrões de argila e partículas friáveis: $10,6 \%$

- Teor de materiais carbonosos: 0,7 \%

- Teor de impurezas orgânicas: 1,38 \%

- Massa específica: $2,60 \mathrm{Kg} / \mathrm{dm}^{3}$

- Massa unitária: 1,16 Kg/dm³

- Teor de umidade (após secagem ao ar livre): $2,12 \%$

- Análise granulométrica: muito fina (zona 1); dimensão máxima característica $=1,2 \mathrm{~mm}$; módulo de finura $=1,77$.

\section{Composição das argamassas}

Para a elaboração das argamassas, foram empregados os seguintes materiais:

- Cimentos: tipo CP II E 32 para os tijolos maciços e tipo CP V ARI para as peças decorativas, marca Ciminas, produzidos pela Holcim Brasil S.A.;

- Sílica Ativa: fornecida pela Empresa Microsílica Tecnologia Indústria e Comércio Ltda;
- Aditivo Superplastificante: tipo Glenium 51 fornecido pela Degussa Construction Chemicals Brasil Ltda.

- Areia Natural: tipo fina, proveniente de portos localizados no Rio Mogi-Guaçu;

Em particular, para a fabricação das peças decorativas, foram empregados materiais complementares:

- Tela de Fibra de Vidro: tipo EGlass Padrão Advantex, fabricada pela Owens-Corning Fiberglass Ltda.;

- Resina Poliuretana de Mamona: fornecida pelo Grupo de Química Analítica e Tecnologia de Polímeros (GQATP) do Instituto de Química de São Carlos - USP;

- Arame de Aço: tipo recozido e galvanizado;

- Tintas: tipo Acrílica Pisos Premium, à base de água, fornecida pela Empresa Dacar Química do Brasil S/A, em conformidade com a norma da ABNT NBR-11702 - Tintas para edificações não industriais - Classificação (1992), nas cores, de acordo com o catálogo, branco (100), preto (022), amarelo demarcação (033), azul (031) e vermelho (2088AQ).

Com base nos estudos de PABLOS (1995) foram elaboradas argamassas nas seguintes proporções: 
- $\quad$ Argamassas para os tijolos maciços, denominadas CRS (tabela 6).

A quantidade de sílica ativa foi estabelecida constante e igual a $10 \%$ da massa de cimento. AïTCIN (2000) sugere uma dosagem de sílica ativa entre $8 \%$ e $10 \%$ em relação à massa de cimento, para a elaboração de concretos de alto desempenho. NEVILLE (1997) estabelece que a presença de 5\% a $10 \%$ de sílica ativa em relação à massa de cimento reduz consideravelmente a permeabilidade dos concretos.

A quantidade de água presente nas misturas foi estabelecida através da determinação da umidade ótima de compactação (ABNT NBR 12023 - Solocimento - Ensaio de Compactação, 1992), para cada composição, uma vez que o processo de fabricação dos tijolos maciços utiliza o sistema de prensagem através de uma prensa hidráulica. Os ensaios foram realizados no Laboratório de Estradas do Departamento de Transportes da Escola de Engenharia de São Carlos - USP. Nestes ensaios, a quantidade de água é especificada em porcentagem, relativa à massa de água em relação à massa dos demais materiais secos presentes na composição.

As composições CRS foram submetidas aos ensaios de resistência à compressão (ABNT NBR7215 Cimento Portland: Determinação da Resistência à Compressão), absorção de água (ABNT NBR9778 Argamassa e Concreto Endurecidos: Determinação da
Absorção de Água por Imersão), permeabilidade ao ar (ASTM C577-96: Standard Test Method for Permeability of Refractories e Innocentini \& Pandolfelli, 1999) e solubilização (ABNT NBR10006 - Procedimento para Obtenção do Extrato Solubilizado).

- Argamassas para as peças decorativas, denominadas CRSA (tabela 7).

Para as composições das argamassas correspondentes às peças decorativas foi utilizada uma areia natural, em quantidade de $40 \%$ em relação à massa de resíduo, a fim de melhorar a coesão da mistura e proporcionar uma boa trabalhabilidade da argamassa, adequando-a ao processo de fabricação das peças decorativas. A areia utilizada está classificada como uma areia fina, de acordo com os limites granulométricos da norma referente. A dimensão máxima característica é $2,4 \mathrm{~mm}$ e o módulo de finura 2,18 . A quantidade de sílica ativa foi estabelecida constante e igual a $5 \%$ da massa de cimento. A quantidade de água empregada foi a que proporcionou uma consistência de $200 \pm 10$ mm, na mesa de abatimento.

As composições CRSA foram submetidas aos ensaios de resistência à compressão (ABNT NBR7215 - Cimento Portland: Determinação da Resistência à Compressão) e absorção de água (ABNT NBR9778 - Argamassa e Concreto Endurecidos: Determinação da Absorção de Água por Imersão).

Tabela 6 - Composições com cimento, resíduo e sílica

\begin{tabular}{|c|c|c|c|}
\hline Denom. & $\begin{array}{l}\text { Cimento : Resíduo } \\
\text { traço }\end{array}$ & $\begin{array}{l}\text { ica : Água } \\
\text { composição }\end{array}$ & $\begin{array}{c}\text { Água/Mat.sec. } \\
(\%)\end{array}$ \\
\hline CRS1 & $1: 1: 0,10: 0,30$ & $41,6 \%: 41,6 \%: 4,16 \%: 12,64 \%$ & 14,3 \\
\hline CRS3 & $1: 3: 0,10: 0,60$ & $21,3 \%: 63,9 \%: 2,13 \%: 12,67 \%$ & 14,7 \\
\hline
\end{tabular}

Tabela 7 - Composições com cimento, resíduo, areia natural, sílica e aditivo

\begin{tabular}{|c|c|c|c|}
\hline Denom. & $\begin{array}{l}\text { Cimento : Resíduo : Areia Natura } \\
\text { traço }\end{array}$ & $\begin{array}{l}\text { al : Sílica : Aditivo : Água } \\
\text { composição }\end{array}$ & $\begin{array}{l}\text { Consistência } \\
(\mathrm{mm})(200 \pm 10)\end{array}$ \\
\hline CRSA3 & $1: 3: 1,2: 0,05: 0,01: 1,14$ & $15,62 \%: 46,88 \%: 18,75 \%: 0,78 \%: 0,15 \%: 17,81 \%$ & 196 \\
\hline CRSA4 & $1: 4: 1,6: 0,05: 0,01: 1,38$ & $12,43 \%: 49,75 \%: 19,9 \%: 0,62 \%: 0,12 \%: 17,16 \%$ & 199 \\
\hline
\end{tabular}



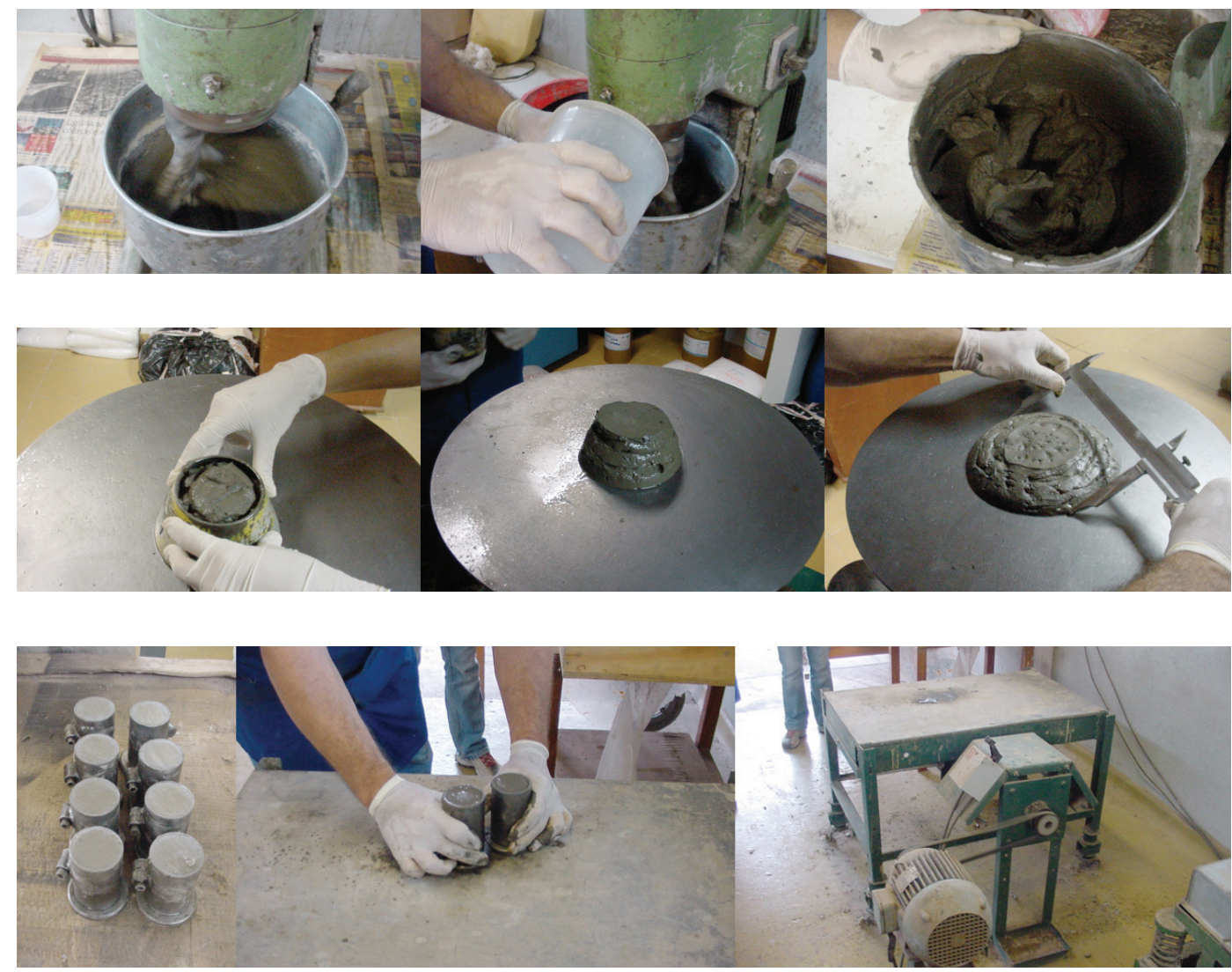

Figura 3: Preparação das argamassas. Fonte: Javier Mazariegos Pablos.

Figura 4: Ensaio de consistência das argamassas CRSA. Fonte: Javier Mazariegos Pablos.

Figura 5: Moldagem dos corpos-de-prova com adensamento em mesa vibratória. Fonte: Javier Mazariegos Pablos.
Verificação do desempenho das matrizes solidificadas

- Resistência à compressão e absorção de água das matrizes CRS e CRSA:

Tabela 8 - Resistência média à compressão e absorção média de água (CRSA)

\begin{tabular}{lccc} 
Composição & $\begin{array}{r}\text { Idade } \\
\text { (dias) }\end{array}$ & $\begin{array}{c}\text { Resistência à } \\
\text { Compressão } \\
\text { (MPa) }\end{array}$ & $\begin{array}{c}\text { Absor- } \\
\text { ção de } \\
\text { Água(\%) }\end{array}$ \\
\hline CRS1 & 28 & 41,3 & 3,96 \\
CRS3 & 28 & 32,8 & 7,98 \\
\hline
\end{tabular}

Tabela 9 - resistência média à compressão e absorção média de água (CRSA)

\begin{tabular}{llll} 
Composição & $\begin{array}{c}\text { Idade } \\
\text { (dias) }\end{array}$ & $\begin{array}{c}\text { Resistência à } \\
\text { Compressão } \\
(\mathrm{MPa})\end{array}$ & $\begin{array}{c}\text { Absorção de } \\
\text { Água(\%) }\end{array}$ \\
\hline CRSA3 & 7 & 9,3 & 16,15 \\
\hline CRSA4 & 7 & 5,8 & 17,70
\end{tabular}

- $\quad$ Permeabilidade ao ar das matrizes CRS:

A permeabilidade é uma propriedade que tem despertado bastante interesse na tecnologia das argamassas e dos concretos, uma vez que determina a susceptibilidade destes materiais a processos de degradação por ataques químicos, quando submetidos a ambientes agressivos. Portanto, a estimativa da durabilidade de argamassas e concretos está diretamente vinculada à sua permeabilidade, uma vez que determina a facilidade com que gases ou líquidos agressivos penetram e atacam suas estruturas. No caso de resíduos sólidos solidificados em matrizes de cimento, esta propriedade torna-se importante, pois determina o quanto as matrizes estarão sujeitas à degradação, no caso de deposição em aterros.

A determinação da estimativa da permeabilidade ao ar foi efetuada aplicando modelo e procedimentos propostos pela Norma ASTM C577-96, e com os 
dados experimentais ajustados segundo a equação de Forchheimer [1].

$$
\frac{\Delta P}{L}=\frac{\mu}{K_{1}} V_{S}+\frac{\rho}{K_{2}} V_{S}^{2}
$$

Tabela 10 - Permeabilidade ao ar das matrizes CRS

$\begin{array}{lll}\text { Amostra } & \mathrm{K} 1(\mathrm{~m} 2) & \mathrm{K} 2(\mathrm{~m}) \\ \text { CRS1 } & 5,57 \mathrm{E}-17 & 2,97 \mathrm{E}-15 \\ \text { CRS3 } & 1,43 \mathrm{E}-16 & 2,42 \mathrm{E}-14\end{array}$

Os resultados obtidos indicam que as argamassas tipo CRS possuem uma permeabilidade ao ar aproximadamente igual à dos concretos comuns $(\sim \mathrm{K} 1=5,12 \times 10-16, \mathrm{~K} 2=8,99 \times 10-14)$ e dos concretos refratários $(\sim \mathrm{K} 1=3,46 \times 10-16, \mathrm{~K} 2=$ $1,25 \times 10-14)$ (INNOCENTINI; e outros, 2001).

Isso indica que as composições investigadas para a fabricação dos tijolos maciços, no seu estado endurecido, apresentaram excelente desempenho quanto à estimativa de durabilidade e não estarão sujeitas à fácil degradação quando depositadas em aterros.

- Solubilização das matrizes CRS e CRSA:

Tabela 11 - Análise do extrato solubilizado das composiç̃es CRS1

\begin{tabular}{|c|c|c|c|}
\hline \multirow[t]{2}{*}{ Elemento } & \multicolumn{2}{|c|}{ Solubilização (mg/L) } & \multirow{2}{*}{$\begin{array}{l}\text { Solubilização } \\
\text { L.M. (mg/L) }\end{array}$} \\
\hline & 28 dias & 365 dias & \\
\hline Al & nd & nd & 0,2 \\
\hline $\mathrm{Fe}$ & nd & nd & 0,3 \\
\hline Cr total & nd & nd & 0,05 \\
\hline
\end{tabular}

nd - elemento não detectado

L.M. - Limite Máximo estabelecido pela ABNT NBR10004 (2004)

Tabela 12 - Análise do extrato solubilizado das composições CRS3

\begin{tabular}{|c|c|c|c|}
\hline \multirow[t]{2}{*}{ Elemento } & \multicolumn{2}{|c|}{ Solubilização (mg/L) } & \multirow{2}{*}{$\begin{array}{c}\text { Solubilização } \\
\text { L.M. (mg/L) }\end{array}$} \\
\hline & 28 dias & 365 dias & \\
\hline Al & 0,08 & nd & 0,2 \\
\hline $\mathrm{Fe}$ & nd & nd & 0,3 \\
\hline Cr total & nd & nd & 0,05 \\
\hline
\end{tabular}

nd - elemento não detectado

L.M. - Limite Máximo estabelecido pela ABNT NBR10004 (2004)
Tabela 13 - Análise do extrato solubilizado das composições CRSA3

\begin{tabular}{lll} 
Elemento & $\begin{array}{l}\text { Solubilização }(\mathrm{mg} / \mathrm{L}) \\
28 \text { dias }\end{array}$ & $\begin{array}{c}\text { Solubilização } \\
\text { L.M. }(\mathrm{mg} / \mathrm{L})\end{array}$ \\
$\mathrm{Al}$ & 0,14 & 0,2 \\
$\mathrm{Fe}$ & $\mathrm{nd}$ & 0,3 \\
\hline $\mathrm{Cr}$ total & 0,02 & 0,05 \\
\hline
\end{tabular}

nd - elemento não detectado

L.M. - Limite Máximo estabelecido pela ABNT NBR10004 (2004)

Tabela 14 - Análise do extrato solubilizado das composições CRSA4

\begin{tabular}{lll} 
Elemento & $\begin{array}{l}\text { Solubilização }(\mathrm{mg} / \mathrm{L}) \\
28 \text { dias }\end{array}$ & $\begin{array}{l}\text { Solubilização } \\
\text { L.M. }(\mathrm{mg} / \mathrm{L})\end{array}$ \\
\hline $\mathrm{Al}$ & 0,25 & 0,2 \\
$\mathrm{Fe}$ & nd & 0,3 \\
\hline Cr total & 0,08 & 0,05 \\
\hline
\end{tabular}

nd - elemento não detectado

L.M. - Limite Máximo estabelecido pela ABNT NBR10004 (2004)

\section{Fabricação dos tijolos e das peças decorativas}

Através da análise dos resultados obtidos, optamos por fabricar os tijolos maciços com a composição CRS3 e as peças decorativas com a composição CRSA3.

O projeto dos tijolos maciços foi concebido, inicialmente, para ser utilizado na execução de alvenarias não-portantes (vedação). Ao mesmo tempo, o design estabelecido para os tijolos proporciona modulação e encaixes que podem reduzir significativamente o consumo da argamassa de assentamento, além de facilitar a execução das instalações prediais.

O processo de fabricação dos tijolos utilizou uma prensa hidráulica, com capacidade de prensagem de 3 toneladas, possibilitando a manutenção da regularidade dimensional do tijolo, assim como de suas características físicas.

Para a produção das peças decorativas, foram elaboradas 3 (três) fôrmas em madeira que representassem obras de Piet Mondrian. A escolha do artista se deu pela sua grande importância 

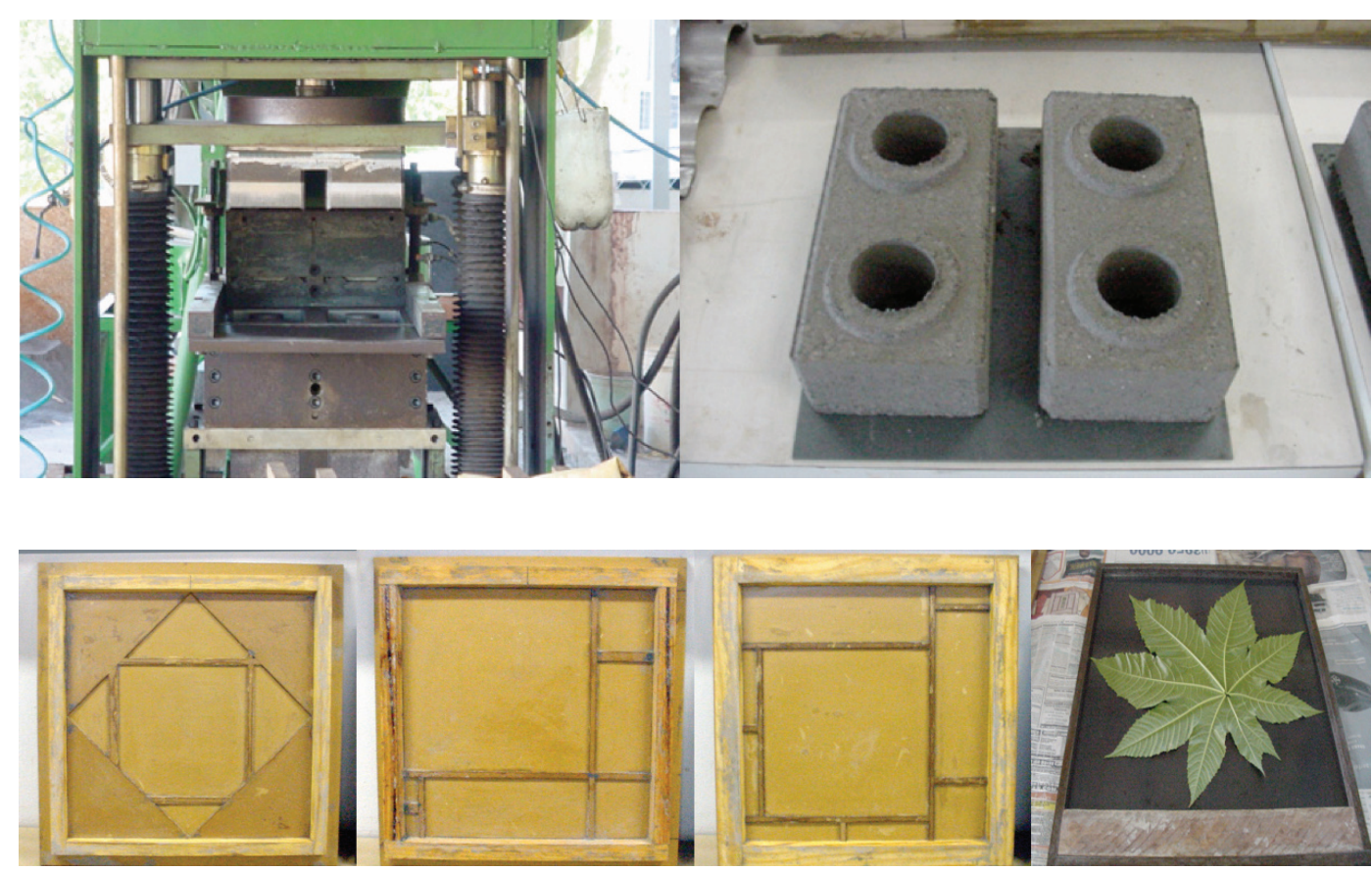

Figura 6: Fabricação dos tijolos maciços. Fonte: Javier Mazariegos Pablos.

Figura 7: Fôrmas em madeira para reprodução das obras de Mondrian e follha de mamona. Fonte: Javier Mazariegos Pablos. na Arte Moderna com a conquista progressiva da abstração pura. Além disso, a reprodução de suas obras, por possuírem padrões geométricos, em madeira, material necessário à execução das fôrmas, é relativamente simples, possibilitando o desenvolvimento da pesquisa.

As fôrmas foram elaboradas no Laboratório de Maquetes e Modelos do Departamento de Arquitetura e Urbanismo da Escola de Engenharia de São Carlos - USP. As obras representadas são: "Tableau 1. Lozenge with Four Lines and Gray" (1926); "Tableau 2" (1922); e "Composition" (1930), respectivamente. Ainda investigou-se a estampagem da folha de mamona, por haver facilidade em encontrá-la e por constituir parte de testes já iniciados por Javier Mazariegos Pablos, com base em idéias e trabalhos da artista plástica Elissa Laura Melchiori (São Carlos - SP).

As fôrmas em madeira foram impermeabilizadas com resina poliuretana de mamona para evitar que imperfeições da madeira prejudicassem o acabamento das peças, facilitar a desmoldagem e aumentar a vida útil da fôrma. No processo de fabricação, as fôrmas, inicialmente, foram preenchidas pela metade com argamassa na composição CRSA3 e vibradas pelo processo de adensamento mecânico, para depois ser colocada a tela de fibra de vidro e completado o restante com a argamassa. A tela de fibra de vidro foi utilizada apenas nas bordas, com largura de 4 (quatro) cm, para evitar que as peças apresentassem fissuras, como ocorrido com as composições investigadas anteriormente, decorrentes por tensões provocadas por retração. Assim, as peças passaram por um segundo processo de vibração e foram cobertas, permanecendo em processo de cura por 3 (três) dias.

Após o período de cura, as peças foram desmoldadas. Cabe ressaltar que foram usados ganchos em arame de aço galvanizado, para que fosse possível pendurar as peças depois de prontas.

Para finalizar o processo de produção, as peças foram pintadas, conforme figura 10. 

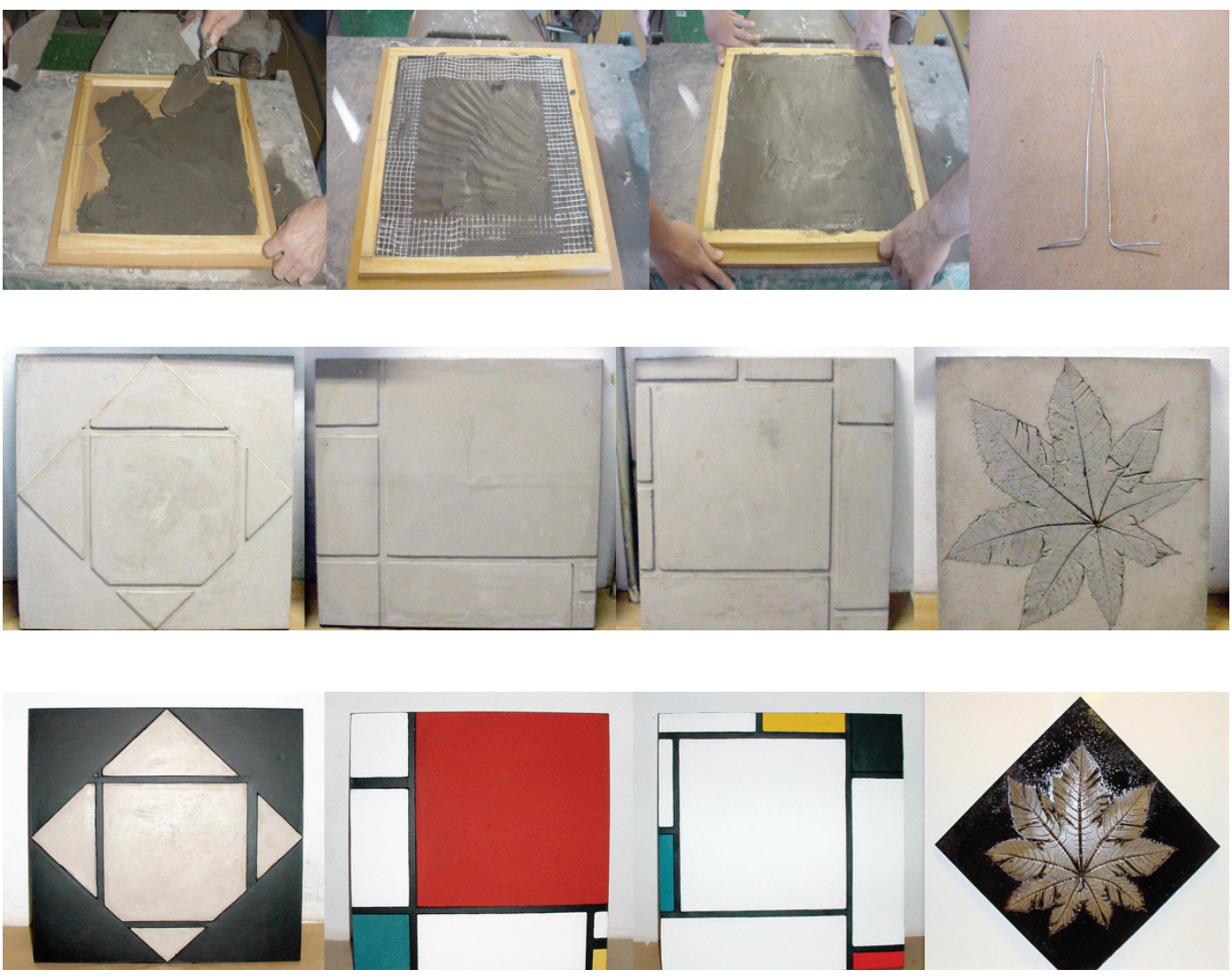

Figura 8: Produção das peças: preenchimento, colocação da tela de nylon e arame de aço. Fonte: Javier Mazariegos Pablos.

Figura 9: Peças decorativas desmoldadas, Piet Mondrian e folha de mamona. Fonte: Javier Mazariegos Pablos.

Figura 10: Peças pintadas, Piet Mondrian e folha de mamona. Fonte: Javier Mazariegos Pablos.

\section{Propriedades dos Tijolos Maciços}

- Resistência à compressão média dos tijolos (28 dias) = 4,4 MPa;

Desvio padrão $=0,32$

Absorção de água média dos tijolos (28 dias) = $11,3 \%$

Tabela 15: Análise do extrato solubilizado dos tijolos (28dias)

\begin{tabular}{lll} 
Elemento & Solubilização (mg/L) & Solubilização L.M. (mg/L) \\
\hline $\mathrm{Al}$ & nd & 0,2 \\
$\mathrm{Fe}$ & 0,10 & 0,3 \\
\hline Cr total & 0,06 & 0,05 \\
\hline
\end{tabular}

nd - elemento não detectado

L.M. - Limite Máximo estabelecido pela ABNT NBR10004 (2004)

\section{Análises e conclusões}

A metodologia estabelecida revelou-se adequada na investigação da viabilidade técnica de reutilização do resíduo sólido industrial, proveniente das areias de fundição, através da técnica de solidificação/ estabilização em matrizes de cimento Portland, podendo ser empregada em estudos semelhantes com outros resíduos sólidos industriais.

O resíduo sólido constituído pelas areias de fundição aglomeradas com argila, empregado na presente pesquisa, apresentou caracterização que o classifica como "não perigoso e não inerte", ou seja, Classe IIA, conforme ABNT NBR-10004 (2004). Ao mesmo tempo, atende os parâmetros estabelecidos pela CETESB, em "Procedimentos para o Gerenciamento de Areia de Fundição" (2007), indicando a possibilidade de reutilização do resíduo na confecção de artefatos de cimento. 
Os tijolos maciços, fabricados com a composição CRS3, apresentaram resultados satisfatórios quanto aos requisitos mecânico e físico (resistência à compressão e absorção de água). A norma ABNT NBR8491 (1984) - Tijolo Maciço de Solo-cimento - Especificação estabelece as seguintes condições para a aceitação dos tijolos:

. A amostra ensaiada de acordo com a NBR-8492 não deve apresentar a média dos valores de resistência à compressão menor do que 2,0 MPa, nem valor individual inferior a 1,7 $\mathrm{MPa}$

A amostra ensaiada de acordo com a NBR-8492 não deve apresentar a média dos valores de absorção de água maior do que $20 \%$, nem valores individuais superiores a $22 \%$.

Portanto, os tijolos maciços obtidos atendem plenamente os critérios de aceitação estabelecidos na especificação brasileira, comprovando a viabilidade técnica para a aplicação na execução de alvenarias.

A análise do extrato solubilizado dos tijolos maciços indica a presença do metal $\mathrm{Cr}$ excedendo os limites máximos estabelecidos pela ABNT NBR-10004 (2004). Entretanto, a Companhia de Tecnologia de Saneamento Ambiental, em publicação CETESB (2007), não estabelece nenhuma restrição quanto

Figura 11: Exemplar e ensaio de resistência à compressão dos tijolos. Fonte: Javier Mazariegos Pablos. ao desempenho químico das matrizes solidificadas, somente determina parâmetros de reutilização para o resíduo sólido areia de fundição.
Apesar da viabilidade econômica não ser objeto do presente trabalho, uma análise financeira superficial, do processo de reutilização do resíduo na fabricação de tijolos, indica que para cada 3 toneladas de resíduo sólido são necessários uma tonelada de cimento ( R R $400,00)$ e 100 quilogramas de sílica ativa $(\sim R \$ 80,00)$, além dos custos referentes à preparação da argamassa e fabricação ( R\$400,00), totalizando um custo de aproximadamente $R \$ 880,00$. Essas quantidades determinam possibilidade de fabricar 1500 tijolos que caso sejam vendidos por $\mathrm{R} \$ 0,40$ a unidade proporcionariam um retorno de $\mathrm{R} \$ 600,00$. Isso estabelece um custo de $R \$ 220,00$ para a reutilização de 3 toneladas de resíduo, enquanto o custo para depositar essa quantidade em um aterro industrial atinge o valor de aproximadamente $\mathrm{R} \$ 600,00$.

As matrizes CRSA3 apresentaram resultados, de resistência à compressão e absorção de água, satisfatórios ao objetivo de utilização na confecção de peças decorativas. A análise do extrato solubilizado da matriz CRSA3 indica que os metais $\mathrm{Al}$, Fe e $\mathrm{Cr}$ foram solubilizados em quantidades inferiores aos limites máximos.

O resultado dos elementos decorativos finalizados foi extremamente satisfatório, por demonstrar fiel reprodução das figuras e impecável acabamento da argamassa, comprovando a viabilidade da fabricação. Além disso, apresentaram ótima repercussão no meio acadêmico, indicando boa aceitação no mercado e potencial para geração de emprego e renda com a produção das peças.
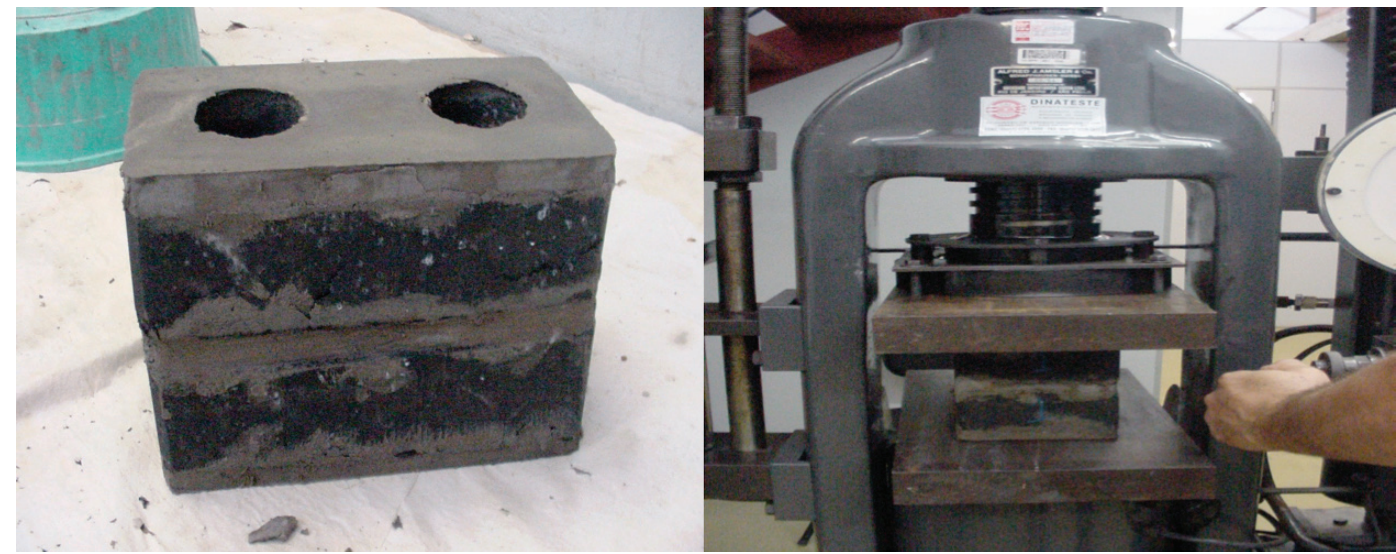
Da mesma forma, uma análise financeira superficial, do processo de fabricação das peças decorativas, indica que 3 toneladas de resíduo propiciam a fabricação de cerca de 1000 peças, a um custo de $\sim R \$ 15,00$ por peça. Cada peça pode ser vendida por $\sim R \$ 30,00$, gerando um lucro de $\mathrm{R} \$ 15.000,00$.

Evidentemente, as análises financeiras apresentadas não comprovam a viabilidade econômica dos processos de reutilização investigados, porém são indicativos da potencialidade de implantação, cabendo às empresas interessadas um estudo mais aprofundado.

Por fim, podemos concluir que o presente trabalho propõe uma metodologia adequada aos estudos para reutilização de resíduos sólidos industriais na fabricação de artefatos de cimento. Ao mesmo tempo, comprova a viabilidade técnica da reutilização do resíduo sólido, constituído pelas areias de fundição aglomeradas com argila, para a fabricação de tijolos maciços, visando aplicação na execução de alvenarias, e para a confecção de elementos de decoração.

\section{Referencias bibliográficas}

AMERICAN SOCIETY FOR TESTING AND MATERIALS ASTM C577; Standard Test Method for Permeability of Refractories. West Conshocken, PA., 1996.

ASSOCIAÇÃO BRASILEIRA DE NORMAS TÉCNICAS ABNT; NBR 7211; Agregados para Concreto - Especificação. 2005

-NBR 8491: Tijolo Maciço de Solo-cimento - Especificação. 1984.

;NBR 8492; Tijolo Maciço de Solo-cimento Determinação da Resistência à Compressão e da Absorção de Água. 1984.

-NBR 9778; Argamassa e Concreto Endurecidos - Determinação da Absorção de Água por Imersão. 2005 2004

NBR 10004; Resíduos Sólidos - Classificação.

;NBR 10005; Procedimento para Obtenção de Extrato Lixiviado de Resíduos Sólidos. 2004.

NBR 10006: Procedimento para Obtenção de Extrato Solubilizado de Resíduos Sólidos. 2004.

:NBR 10007; Amostragem de Resíduos Sólidos. 2004
-NBR 12023; Solo-cimento - Ensaio de Compactação. 1992

ADASKA, W. S.; Solidification and Stabilization of Wastes Using Portland Cement. Portland Cement Association, EB071, $2^{\text {nd }}$ ed., Skokie, IL, 1998.

AïTCIN, P.C.; Concreto de Alto Desempenho. PINI, São Paulo, 2000.

ALBERONI, V.G.: YOKOYAMA, L.; DWECK, J.; Estudo de Processo de Solidificação/Estabilização de Resíduo Industrial Contendo Níquel. V Congresso Brasileiro de Análise Térmica e Calorimetria, Anais, 2006.

BHATTY, J.I.; Stabilization of Heavy Metals in Portland Cement, Sílica Fume / Portland Cement and Masonry Cement Matrices. Portland Cement Association, RP348, Skokie, IL, 1999.

COMPANHIA DE TECNOLOGIA DE SANEAMENTO AMBIENTAL - CETESB, 1999. www.cetesb.sp.gov. br/institucional/portugues_solo.asp, acesso em 14/09/2007.

- Procedimentos para Gerenciamento de Areia de Fundição. Decisão de Diretoria no 152/2007/C/E. São Paulo, agosto/2007.

CLAUDIO, J.R.; Resíduos Sólidos Perigosos - Solidificação de Lamas Tóxicas com Cimentos. Dissertação de Mestrado, Escola Politécnica - USP, São Paulo, 1987.

CONNER, J.R.; Guide to Improving the Effectiveness of Cement-Based Stabilization/Solidification. Portland Cement Association, EB211, Skokie, IL, 1997.

HANNA, R.A.; Estudo em Escala de Laboratório da Fixação de Metais em Matriz de Cimento Tendo em Vista a Disposição Final de Rejeitos Industriais Perigosos. Dissertação de Mestrado, EPUSP, São Paulo, 1990

Estudo da Estabilização por Solidificação de Produtos Tóxicos em Cimento Portland: Uma Análise em Nível Microestrutural. Tese de Doutorado, EPUSP, São Paulo, 1996

INNOCENTINI, M.D.M.: PANDOLFELLI, V.C.: Considerações sobre a estimativa da permeabilidade em concretos refratários através das equações de Darcy e Forchheimer. Cerâmica, vol.45, n.292-293, 10p., São Paulo, 1999.

INNOCENTINI, M.D.M.; STUDART, A.R.; PILEGGI, R.G. PANDOLFELLI, V.C.; Perfil de permeabilidade em concretos refratários. Cerâmica, vol. 47, n.301, 6p., São Paulo, 2001

MARAGNO, A.L.F.C.; Solidificação de Lodo ao Cromo de Curtume em Matriz de Cimento. Tese de Doutorado, EESC-USP, 1999

MERRITT, S.D.; BATCHELOR, B.; Applications of Soil and Cement Chemistry to Stabilization/Solidification. Transportation Research Record, n.1424, p. 1-7, 1993.

NEVILLE, A.M.; Propriedades do Concreto. Tradução: Salvador E. Giammusso, PINI, 2a Edição, São Paulo, 1997. 
OLIVEIRA R.C. Encapsulamento de Areia de Fundição de Descarte em Matriz de Cimento. Dissertação de Mestrado, EESC-USP, 1996.

PABLOS, J.M.; Utilização do Resíduo Sólido Gerado pelo Descarte das Areias de Fundição Aglomeradas com Argila no Setor de Construção Civil. Dissertação de Mestrado, EESC-USP, 1995.

PINTO, C.A.; Estabilização por Solidificação em Cimento do Resíduo do Curtimento de Couro Contendo Cromo. Dissertação de Mestrado, EPUSP, São Paulo, 2001
POON, C.S.; CLARK, A.I.; PERRY, R.; Permeability Study on the Cement Based Solidification for the Disposal of Hazardous Wastes. Cement and Concrete Research, V. 16, p. 161-172, EUA, 1986

SILVA, TV: LANGE, LC: TELLO, C. C. : TEIXEIRA, L.A.V Estudo Comparativo de Normas de Lixiviação Aplicadas a Resíduos Perigwosos Solidificados/Estabilizados em Cimento. XXVIII Congresso Interamericano de Ingeniería Sanitária y Ambiental, Anais, México, 2002.

WILK. C.M.; Stabilization of Heavy Metal with Portland Cement: Research Synopsis. Portland Cement Association, IS007, Skokie, IL, 1997. 


\title{
Reuse of the industrial solid waste, consisting for foundry sands, in the confection of massive bricks and decorative pieces
}

Javier Mazariegos Pablos, Eduvaldo Paulo Sichieri, Rafaela Lino Izeli

\begin{abstract}
The present work is a result of a research that investigated the technical viability for the reuse of the solid waste generated by foundry sands agglomerated with clay, for application in the sector of the civil construction and in decorative pieces. For that, the investigation established a methodology, which evaluated the stabilization of the waste in solidified matrices of Portland cement, improved with the addiction of silica fume and/or fluidificant additive. Two compositions had been used in the confection of massive bricks and decorative pieces. The obtained bricks had been submited to tests of compressive strength, water absorption and solubilization, The obtained results proved the technical viability for apply the briks in the execution of masonry and to produce decorative pieces, that which presenting excellent aggregated value and potencial to commercialize them.
\end{abstract}

Keywords: industrial solid waste, solidification/stabilization, reuse.

\section{Reutilización del residuo sólido industrial generado por arenas de fundición en la fabricación de ladrillos macizos y piezas decorativas}

Javier Mazariegos Pablos, Eduvaldo Paulo Sichieri, Rafaela Lino Izeli

\section{Resumen}

El trabajo, ora presentado, es resultado de investigación que estudió la factibilidad técnica para la reutilización del residuo sólido generado por las arenas de fundición hechas con arcilla, en el sector de la construcción y en piezas decorativas. Para eso, la investigación estableció una metodología que evaluó la estabilización del residuo en matrices solidificadas de cemento Portland, mejoradas por medio de adición de sílica activa y/o aditivo reductor de agua. Dos composiciones fueron utilizadas en la fabricación de ladrillos macizos y en la confección de piezas decorativas. Los resultados obtenidos confirman la factibilidad técnica para la aplicación de los ladrillos en la ejecución de mamposterías y para la fabricación de piezas decorativas, las cuales presentaron excelente valor agregado y óptimo potencial de comercialización.

Palabras clave: residuos sólidos industriales, solidificación/estabilización, reutilización. 